\title{
A perícia médico-legal e o ensino: dissidências e discussões na Sociedade Brasileira de Neurologia, Psiquiatria e Medicina Legal*
}

\author{
Forensic medical examinations and teaching: \\ disagreements and discussions within the Brazilian Society \\ of Neurology, Psychiatry, and Forensic Medicine
}

\section{Ede Cerqueira}

Doutoranda em História das Ciências e da Saúde/Casa de Oswaldo Cruz/Fiocruz. Av. Brasil, 4365, Manguinhos 21040-900 - Rio de Janeiro - RJ - Brasil

dy_cb@hotmail.com
CERQUEIRA, Ede. A perícia médico-legal e o ensino: dissidências e discussões na Sociedade Brasileira de Neurologia, Psiquiatria e Medicina Legal. História, Ciências, Saúde - Manguinhos, v.22, n.2, abr.-jun. 2015, p.641-649.

\section{Resumo}

Observando a influência da medicina legal na constituição do campo psiquiátrico, este texto analisa os debates ocorridos entre maio e julho de 1918 na Sociedade Brasileira de Neurologia, Psiquiatria e Medicina Legal sobre o uso das perícias médico-legais como material de estudo para o curso de Medicina Pública da Faculdade de Medicina do Rio de Janeiro. A intenção é perceber como a controvérsia desenvolveu-se na referida sociedade, observando como essa instituição científica influenciou na constituição das formações teórica e prática do perito médico.

Palavras-chave: história da psiquiatria; medicina legal; perícia; ensino médico.

\section{Abstract \\ In order to observe the influence wielded by forensic medicine in the development of the field of psychiatry in Brazil, this research note analyzes the debates that took place from May to July 1918 within the Brazilian Society of Neurology, Psychiatry, and Forensic Medicine over the use of forensic medical examinations as course material in the study of Public Medicine at the Rio de Janeiro School of Medicine. The focus is on how the controversy unfolded within the Society and how this scientific organization influenced the institution of the theoretical and practical training of medical experts.}

Keywords: history of psychiatry; forensic medicine; forensic medical examinations; medical teaching. 
$\mathrm{N}^{a}$ minha pesquisa de mestrado, analiso a história da Sociedade Brasileira de Neurologia, Psiquiatria e Medicina Legal (SBNPML) ${ }^{1}$ observando sua participação na institucionalização da psiquiatria brasileira no período de 1907 a 1933. Nesta nota de pesquisa analiso, especificamente, os debates a respeito do desenvolvimento do ensino prático de medicina legal que foram registrados nas atas da SBNPML e publicados como boletins, no ano de 1918, no periódico da instituição. Este foi criado pelos médicos Juliano Moreira e Afranio Peixoto em 1905, com o nome de Arquivos Brasileiros de Psiquiatria, Neurologia e Ciências Afins. Com a fundação da SBNPML em 1907, o periódico tornou-se o órgão de divulgação oficial da sociedade, passando a ser denominado Arquivos Brasileiros de Psiquiatria, Neurologia e Medicina Legal de 1908 a 1918, até que, em 1919, logo após a controvérsia analisada aqui, foi criado um periódico novo, sem o termo "medicina legal" em seu título - Arquivos Brasileiros de Neuriatria e Psiquiatria (1919-1956).

Por meio da análise da atas da SBNPML, entrei em contato com a controvérsia aqui analisada com o objetivo de perceber como tal disputa foi debatida na instituição e como essa contenda se articulou com temas mais amplos, relativos à especialização e à institucionalização das ciências médicas no Brasil. Para ter uma ideia mais abrangente do contexto em que tal disputa ocorreu, utilizei também como fontes notas de jornais da época, ${ }^{2}$ pesquisados na Hemeroteca Digital Brasileira, da Biblioteca Nacional.

\section{A controvérsia sobre o uso das perícias médico-legais no curso de medicina pública}

A controvérsia, intitulada nas atas da SBNPML como "Perícia e ensino", começou a ser discutida nas sessões dessa entidade em maio de 1918 e prolongou-se em acirrados debates até julho do mesmo ano, envolvendo questões constitutivas do campo da medicina legal, como o sigilo na perícia e a formação especializada do médico-legista. Contudo, não foi na SBNPML que tal contenda teve início. Ela parece ter se desenvolvido a partir do "protesto" apresentado, em outubro de 1917, por dois peritos do Serviço Médico-Legal - Henrique Rodrigues Caó ${ }^{3}$ e José Francisco Cunha Cruz ${ }^{4}$ ao então diretor Luiz Antonio Moretzsohn Barbosa $^{5}$ contra o funcionamento das aulas de medicina legal do recém-instalado curso de medicina pública na sede do SBNPML.

O curso foi criado no início de 1917, como um curso facultativo de especialização para médicos e doutorandos da Faculdade de Medicina do Rio de Janeiro, por iniciativa de um grupo de professores formado por Júlio Afranio Peixoto, Ernesto Nascimento Silva, Raul Leitão da Cunha e Diógenes de Almeida Sampaio (SBPNML, maio-set. 1918, p.122). Em seu programa, o curso condensava as matérias de higiene e medicina legal em uma mesma disciplina, visando "dar um preparo suplementar aos médicos que pretendam especializações em assuntos sanitários e de medicina legal" (Brasil, 10 fev. 1918, p.7). As aulas de medicina legal e higiene teriam um caráter eminentemente prático, e, segundo noticiava o periódico O Imparcial (Curso..., 1 jun. 1917, p.1), logo após a criação do curso, este deveria suprir as deficiências de preparo dos peritos e médicos sanitários, ainda sem prática suficiente nos cursos oficiais de medicina clínica.

O programa de estudos do curso de medicina pública daquele primeiro ano de funcionamento consistia de aulas práticas dedicadas à técnica médico-legal, à técnica sanitária e 
à química forense. Tanto as aulas como os exames do curso eram realizados no laboratório da Escola de Medicina, no laboratório do hospício e no do Gabinete Médico-Legal (Doutores..., 20 dez. 1917, p.8). No gabinete, ou melhor dizendo, no Serviço Médico-Legal, como era oficialmente nomeado desde 1907, os professores do curso de medicina pública realizavam as perícias médico-legais na presença dos alunos, utilizando os relatórios das perícias como material de estudo (SBPNML, maio-set. 1918, p.160). E foi justamente nesse ponto que a polêmica originou-se.

Segundo o médico-legista Rodrigues Caó, ao servir-se "da perícia médico-legal como assunto de exemplificação prática a seus alunos", os professores do curso, mais especificamente o professor de medicina legal e também perito-médico Diógenes Sampaio, feriam "o princípio universal do sigilo pericial” de maneira inaceitável (SBPNML, maio-set. 1918, p.160). Assim, conforme a versão apresentada pelo diretor do Serviço Médico-Legal, Moretzsohn Barbosa, à SBNPML, Caó e Cruz Costa, antes do encerramento das aulas do primeiro ano do curso, teriam lhe enviado uma representação em que faziam alusões a "irregularidades ou inconveniências" por ocasião das aulas práticas de medicina legal do referido curso (SBPNML, maio-set. 1918, p.122).

Barbosa diz que teria encaminhado imediatamente tal representação, acompanhada por outras informações, ao ministro da Justiça interino, Tavares de Lyra, que preferiu esperar o retorno do ministro titular, Carlos Maximilliano, para que este decidisse a questão. As recomendações posteriores deste foram no sentido de que Moretzsohn Barbosa e Aloysio de Castro, então diretor da Faculdade de Medicina do Rio de Janeiro, entrassem em um acordo, o que, segundo o diretor do Serviço Médico, não aconteceu por relutância do seu interlocutor (SBPNML, maio-set. 1918, p.122-124).

O questionamento sobre a utilização ou não de perícias no ensino da medicina legal que ganhou status de "celeuma" nos debates médicos travados no palco das sociedades científicas, como a Academia Nacional de Medicina e a Sociedade de Medicina e Cirurgia do Rio de Janeiro, citados nas atas da SBNPML de 1918 - pode ser relacionado a disputas que remontam ao final do século XIX e princípio do século XX.

\section{O ensino prático da medicina legal}

A cadeira de medicina legal nas faculdades de medicina foi criada pela reforma do ensino superior de 1832, que estabeleceu um programa centrado em aulas teóricas. A cadeira prevaleceu pelo menos até a reforma seguinte, regulamentada em 1882, que tentou dar um caráter mais prático ao programa, com base nos ideais de desenvolvimento de uma "medicina experimental" no Brasil. Entre 1881 e 1882, no contexto dos debates sobre a reforma, o médico Souza Lima ${ }^{6}$ conseguiu autorização para promover um curso de tanatologia forense no necrotério da polícia, como curso prático da cadeira de medicina legal. Dentre as modificações ocorridas no ensino superior após a proclamação da República, o curso de direito passou a ter como obrigatórias as disciplinas de medicina legal e higiene, condensadas, em 1895, na disciplina de medicina pública, o que permaneceu até 1902, quando as duas disciplinas voltaram a ser separadas (Hércules, 2001, p.185). 
Em 1903, Afrânio Peixoto, que já estava trabalhando com Juliano Moreira no Hospício Nacional de Alienados, elaborou um projeto de regulamentação dos serviços da polícia, a pedido do ministro da Justiça e dos Negócios Interiores J.J. Seabra (Maio, 1994, p.76). No mesmo ano, o governo federal estabeleceu as normas para os exames médico-legais, por meio do decreto 4.846, de 15 de junho de 1903, com a adoção de um protocolo de necropsias semelhante ao adotado na Alemanha. Entretanto, médicos não especializados continuavam a ser nomeados para a função de perito, gerando questionamentos sobre a qualidade das perícias (Hércules, 2001, p.185).

Foi nesse contexto de desconfiança quanto à capacidade dos médicos legistas que Afrânio Peixoto, após regressar de viagem de estudos à Europa em companhia do também médico Oscar Rodrigues Alves, foi aprovado no concurso de 1906 para a vaga de professor das cadeiras de medicina legal e higiene da Faculdade de Medicina (Maio, 1994, p.76). Usando, a partir de então, toda a influência que seu cargo e seu prestígio pessoal lhe proporcionavam, Afrânio passou a mover uma campanha contra a má qualidade das perícias oficiais junto a autoridades, a sociedades médico-científicas - como a Academia Nacional de Medicina, da qual já era membro desde 1903 - e ao Instituto de Advogados do Brasil. Como resultado, essas instituições se manifestaram contra a "implementação da lei, com o fim de impedir que laudos imperfeitos continuassem a ir aos tribunais" (Hércules, 2001, p.186). O sucesso de tal campanha rendeu a Afrânio Peixoto sua nomeação, em 1907, como chefe do Gabinete MédicoLegal, que, por força do decreto 6.440, de 30 de março de 1907, passou a ser denominado "Serviço Médico-Legal". O mesmo decreto criou subespecialidades dentro da medicina legal e estabeleceu que os peritos oficiais só poderiam ser nomeados mediante concurso público (Hércules, 2001, p.186).

Somente em 1915, com o decreto 11.530, de 18 de março, conhecido como Lei Maximilliano, ${ }^{7}$ foi permitido o livre acesso dos professores de medicina legal às dependências do Serviço Médico-Legal, acompanhados de pequenas turmas de alunos, sendo autorizados a fazer perícias em suas aulas e tendo seus relatórios reconhecidos como válidos para fins jurídicos. Porém, era feita a ressalva de que algumas das perícias feitas sob sigilo deveriam ser "furtadas aos olhares dos alunos" (Brasil, 18 mar. 1915, art. 185). Ou seja, o texto da lei, ao mesmo tempo que permitia o uso de perícias no ensino, deixava uma brecha para que essa prática fosse contestada, sob a alegação de quebra do sigilo de justiça. Como veremos, dois anos mais tarde, um grupo de dez peritos do Serviço Médico-Legal utilizou tal argumento para se contrapor à realização do curso de medicina pública, gerando toda a controvérsia.

\section{A controvérsia na imprensa diária}

Ao analisar as notícias publicadas em alguns jornais populares no Rio de Janeiro, deparamonos com posicionamentos que variam à medida que a contenda vai tomando forma.

O primeiro posicionamento foi caracterizado pela pouca importância inicial dada à criação do curso, noticiada em pequenas notas, de cinco a dez linhas no máximo, nos meses de fevereiro a maio de 1917, quando as aulas se iniciam. A partir de então, surgiu um segundo posicionamento, voltado para a propaganda do curso, que se estendeu até os festejos de formatura da primeira turma, em dezembro de 1917. Nessa época, as notícias sobre o curso 
tornaram-se mais detalhadas, assumindo, inclusive, um caráter mais propagandista em alguns dos jornais, como, por exemplo, na coluna que Belmiro Valverde, médico e livredocente em higiene na Faculdade de Medicina do Rio de Janeiro, escreveu sobre o curso para o jornal Correio da Manhã. ${ }^{8}$ Ele inicia o texto de forma bem didática, procurando esclarecer aos leitores a importância do curso e da própria disciplina de medicina pública, ao unir a higiene e a medicina legal em uma só cadeira. Para Valverde, tal feito era digno de aplausos pelas extraordinárias vantagens que poderia trazer tanto para a classe médica como para toda a população, apesar das vozes de protesto de alguns médicos, que alegavam a diversidade dos assuntos estudados pelas disciplinas em questão, contra tal união. Defendendo a ideia de que "é preferível evitar a doença a ter que combatê-la" (Valverde, 24 maio 1917, p.2), ele define a importância da higiene, que, a princípio, estava limitada a prestar à "humanidade extraordinário serviço combatendo as moléstias onde quer que elas aparecessem", mas que, ao ampliar seus horizontes de atuação, passou a não mais simplesmente combater, "mas sim a exterminar de vez, nas suas origens, os grandes males". Quanto à medicina legal, o autor a apresenta com a função de "salvaguarda dos interesses sociais, estabelecendo por meios científicos a possibilidade da repressão dos delitos e crimes, permitindo a punição dos culpados e, por conseguinte, mantendo o equilíbrio social, indispensável a vida". Argumentando que a "vida humana é um capital", conclui "que lutar contra a doença é favorecer a principal fonte de renda de uma nacionalidade, garantindo o trabalho e a vida" (p.2).

Nessa mesma linha, o jornal A Rua informava que 31 médicos inscreveram-se no curso, tendo 12 deles feito os exames práticos e, sendo aprovados, em breve receberiam o diploma de médicos legistas e doutores em medicina pública. São citados como formandos: David Madeira, Leonídio Ribeiro Filho, Oscar Dutra e Silva, Paulo de Proença, Murilo de Souza Campos, Nestor da Rosa Martins, Gavião Gonzaga e Mario Dutra (Doutores..., 20 dez. 1917, p.8). No ano seguinte, o Correio da Manhã noticiava de maneira elogiosa, em texto não assinado, a formatura da primeira turma do curso (Um curso..., 18 maio 1918, p.3).

Um terceiro posicionamento começa a aparecer nos jornais a partir de maio de 1918, mês em que deveria iniciar o segundo ano de aulas. Periódicos que pouco haviam se interessado pelo curso passaram a dar amplo destaque para o debate em colunas de primeira página, como o jornal $A$ Noite, ${ }^{9}$ que, na edição de 20 de maio de 1918 (Um monstruoso..., 20 maio 1918, p.1), inicia uma acirrada campanha contra o curso de medicina pública e, na edição seguinte, apresenta o caso como "Um monstruoso atentado à moral: o escandaloso caso do curso de medicina pública" (Um monstruoso..., 25 maio 1918, p.1), baseado nos argumentos apresentados pelos peritos do Serviço Médico-Legal Rodrigues Caó e Cunha Cruz. Primeiro, as notícias alegavam que a presença de alunos durante o procedimento da perícia "feria o sigilo devido à justiça", e, depois, que ia "contra a moral e o pudor", principalmente nos casos de exames de menores e senhoras, que não desejariam ficar expostas aos olhares dos estudantes (Um monstruoso... 25 maio 1918, p.1).

Outros jornais também acompanharam o debate, entretanto não serão analisados neste texto preliminar, pois nosso interesse aqui, ao mencionar a repercussão do caso nos periódicos, é apenas demonstrar o terreno sobre o qual as discussões em torno do caso na SBNPML estavam firmadas. Ou seja, os membros daquela sociedade foram convocados a participar da discussão e posicionar-se sobre a querela no âmbito da instituição, quando a controvérsia já 
era tema de debates acalorados na Academia Nacional de Medicina, no Congresso Nacional e na imprensa não especializada. A SBNPML foi convocada por um dos seus sócios, Ulysses Vianna, em 29 de maio de 1918, com o objetivo de dar um parecer final ao caso (SBPNML, maio-set. 1918, p.149).

\section{A contenda dentro da Sociedade Brasileira de Neurologia, Psiquiatria e Medicina Legal}

Os debates que aconteceram naqueles dias na SBNPML e foram registrados nas suas atas nos contam de um grupo de médicos divididos em duas correntes. De um lado estavam os professores da Faculdade de Medicina do Rio de Janeiro responsáveis pelo curso de medicina pública: Afrânio Peixoto, Nascimento Silva, Leitão da Cunha e Diogenes Sampaio, todos membros fundadores da SBNPML; e, de outro, os peritos oficiais do Serviço Médico-Legal: Rodrigues Caó, Antenor Costa, Miguel Salles, ${ }^{10}$ Suzano Brandão e Moretzsohn Barbosa, contrários à realização do curso de medicina pública nos moldes em que foi estruturado, isto é, servindo-se das perícias para as aulas práticas de medicina legal. Os debates na casa se iniciaram com a apresentação de uma moção de apoio ao curso de medicina pública, encaminhada por Ulysses Vianna, que, no entanto, não foi votada, devido aos protestos apresentados pelos peritos (SBPNML, maio-set. 1918, p.158-159). Apresentamos aqui apenas alguns dos argumentos apresentados pelos participantes dos dois lados da questão.

$\mathrm{O}$ argumento mais forte dos contrários à manutenção do curso nas instalações do Serviço Médico-Legal era que o perito deve sigilo à Justiça sobre suas conclusões relativas ao ato da perícia até o momento do julgamento, quando seu parecer se torna público. Os favoráveis ao curso, no entanto, argumentavam que a perícia é um ato médico ligado à Justiça, e, possuindo caráter público, consequentemente também é um ato público.

O argumento principal dos professores do curso baseava-se no artigo 185 da lei 11.530, de 18 de março de 1915 - que permitia a entrada do professor de medicina legal em repartições policiais e judiciárias com alunos -, e também no costume de os professores usar essa prática desde o século XIX, como admitiu ter feito Souza Lima em carta enviada a Diógenes Sampaio e lida na SBNPML (maio-set. 1918, p.197-198). Em relação ao primeiro argumento, os peritos declaravam que acima dessa lei estava a que regia o funcionalismo público, e que o perito oficial do serviço médico, como funcionário público, ficava restrito às penalidades do artigo 49 da lei 6.439, de 30 de março de 1907, que o impossibilitava de tornar pública qualquer informação obtida em razão de seu ofício (SBPNML, maio-set. 1918, p.120-239).

Após três meses de discussões, o debate se encerra na SBNPML da mesma forma como começou, com a votação de uma moção pela manutenção do funcionamento do curso de medicina pública e apoio aos seus organizadores, em sessão já sem a presença dos peritos. O caso ainda teria outros desdobramentos, que se estenderam pelos anos seguintes, voltando, esporadicamente, a ser mencionado nos debates da SBNPML, na década de 1920. Mas o que nos interessa agora é mapear os grupos de aliados que cada um dos lados da disputa acionou, assim como tentar compreender como esses debates se relacionam com a questão mais ampla da inserção do ensino prático na medicina legal e na medicina como um todo. 
Pelo que foi possível perceber, o grupo dos peritos do Serviço Médico-Legal saía em desvantagem na disputa dentro e fora da SBNPML. O grupo era composto por poucos sócios da agremiação, recém-admitidos em sua maioria, exceto por Miguel Salles, que era membro fundador. Apesar de os componentes do grupo ${ }^{11}$ serem médicos-legistas experientes, não possuíam o mesmo prestígio entre a comunidade médica carioca que alguns professores da faculdade de medicina, como Souza Lima, Afrânio Peixoto, Nascimento Silva, principalmente porque sobre os médicos peritos pesavam acusações - alardeadas nos jornais diários da capital federal desde o final do século XIX - de imperícia e incompetência.

Do outro lado, os professores do curso de medicina pública contavam com o apoio do então ministro da Justiça Carlos Maximilliano, do diretor da Faculdade de Medicina, Aloysio de Castro, de boa parte dos membros da SBNPML, da Academia Nacional de Medicina, da Sociedade de Medicina e Cirurgia do Rio de Janeiro (SBPNML, maio-set. 1918, p.123-238), de parlamentares, como o deputado Flores da Cunha (Um monstruoso..., 25 maio 1918, p.1), e de alguns jornais.

A questão da utilização do ensino prático na formação de especialistas em medicina legal e higiene pública deixa evidente, na troca de acusações, que os dois grupos buscavam demarcar suas esferas de atuação. Os peritos acusavam os professores do curso de não respeitarem a autonomia do Serviço Médico-Legal em relação à faculdade de medicina. Já os professores acusavam os peritos de monopolizar a formação prática do cargo e a utilização das perícias nas dependências do Serviço Médico-Legal. Ambos os lados, ao fim e ao cabo, disputavam como a formação especializada da perícia médica baseada no ensino prático se daria, e quem seria responsável por ela. O que estava em disputa era muito mais que a simples realização de um curso, mas a delimitação de autoridade sobre o campo de formação profissional dos peritos médicos legistas.

\section{NOTAS}

* Este texto é resultado de parte da pesquisa que desenvolvi para minha dissertação de mestrado no Programa de Pós-Graduação em História das Ciências e da Saúde da Casa de Oswaldo Cruz/Fiocruz, sob a orientação da professora Ana Teresa A. Venancio. Ver Cerqueira (2014).

${ }^{1}$ Essa sociedade foi criada por um grupo de médicos em 1907, no Rio de Janeiro, com o objetivo de desenvolver os "ramos do conhecimento médico" que a nomeavam. Entre seus fundadores, destacam-se Juliano Moreira, Afrânio Peixoto, Antonio Austregésilo, Henrique Roxo e Ulysses Vianna, pela participação ativa no desenvolvimento da entidade, assim como no processo de institucionalização da psiquiatria no início do século XX (Notas, out.-dez. 1907, p.435-436).

${ }^{2}$ Os principais jornais pesquisados foram O Imparcial, A Rua, Correio da Manhã, A Noite e Gazeta de Notícias.

${ }^{3}$ Henrique Rodrigues Caó concluiu o curso de medicina em 1904, pela Faculdade de Medicina do Rio de Janeiro, defendendo a tese Correlação hepato-pancreática, e iniciou suas atividades no Serviço Médico-Legal em 1907, como assistente de laboratório (Maury, 1908, p.507).

${ }^{4}$ José Francisco Cunha Cruz era médico-legista da polícia desde 1895. Nesse período, era um dos poucos civis que trabalhavam no Gabinete Médico-Legal; a maioria dos outros médicos-legistas estava integrada ao corpo policial, como o capitão Manoel Thomaz Coelho, o major Manoel Clemente do Rego Barros, o tenente-coronel Antonio José de Moraes e Britto, o capitão Sebastião Martins Villas-Boas Côrtes e o encarregado das análises toxicológicas e professor da faculdade de medicina Antonio Maria Teixeira. Cunha Cruz também mantinha um consultório particular, onde tratava de pacientes acometidos por "moléstias nervosas" e "curava casos de embriaguez", sendo conhecido até 1899, também, por praticar a homeopatia (Sauer, 1895, p.186, 1902, p.179). 


\begin{abstract}
${ }^{5}$ Luiz Antonio Moretzsohn Barbosa (1870-1952) doutorou-se pela Faculdade de Medicina do Rio de Janeiro em 1895, sendo admitido no Serviço Médico-Legal em 1907. Em 1916, após a morte de Jacyntho de Barros, Barbosa assumiu seu lugar na direção do Serviço Médico-Legal (Maury, 1908, p.507; Serviço..., 7 jan. 1916, p.7).

${ }^{6}$ Agostinho José de Souza Lima (1842-1921) doutorou-se pela Faculdade de Medicina do Rio de Janeiro em 1861 e foi professor catedrático de medicina legal na mesma faculdade entre 1877 e 1912. De 1902 a 1916 , foi professor de medicina pública na Faculdade de Direito do Rio de Janeiro.
\end{abstract}

${ }^{7}$ Esse decreto, que reorganizou o ensino secundário e superior na República, ficou conhecido como Lei Maximilliano por ter sido aprovado sob a gestão do então ministro da Justiça e Negócios Interiores Carlos Maximilliano Pereira dos Santos, durante o mandato de Wenceslau Braz como presidente da República (Brasil, 18 mar. 1915).

${ }^{8}$ Periódico criado pelo jovem advogado Edmundo Bittencourt, em parceria com Rui Barbosa, em 1901, que combateu persistentemente os governos ligados às oligarquias estaduais da primeira República, identificandose com a classe média e os ideais de modernização do país. O jornal assumiu uma postura de apoio ao curso de medicina pública desde sua criação em 1917, denunciando um suposto "monopólio" dos peritos, em editoriais assinados por Antonio Leão Velloso, médico, e por Gil Vidal, pseudônimo adotado por Leão Velloso Filho, coeditor do periódico (Garzoni, jan.-jun. 2011, p.158-160).

${ }^{9}$ Jornal criado em 1911 pelo jornalista Irineu Marinho, que se colocou como oposicionista ao governo federal até o final da década de 1920. Possuía um perfil bem popular, com grande circulação e preços baixos (Hemeroteca..., s.d.). Em suas páginas, o uso da perícia no ensino ganhou status de escandaloso atentado à moral. O jornal publicou entrevistas em que envolvidos na controvérsia, como Diógenes Sampaio e Rodrigues Caó, apresentaram suas versões sobre o caso, e também notas do jornalista Medeiros e Albuquerque contra a manutenção do curso de medicina pública.

${ }^{10}$ Miguel Dantas Salles também foi admitido em 1907 como perito do Serviço Médico-Legal; porém, no mesmo ano, participou da fundação da SBNPML. Na controvérsia aqui analisada, desempenhou um papel de destaque como relator do funcionamento do ensino prático da perícia em alguns países da Europa, que havia visitado em 1912.

${ }^{11}$ O grupo era formado por, entre outros, Cunha Cruz (o único que não era membro da SBNPML), Rodrigues Caó, Antenor Costa, Guilherme Rocha, Miguel Salles, Júlio Cesar Suzano Brandão e Moretzsohn Barbosa.

\title{
REFERÊNCIAS
}

BRASIL.

Ministério da Justiça e Negócios Interiores.

Conselho Superior de Ensino. Ata da segunda sessão, realizada em 6 de fevereiro de 1918, sob a presidência do presidente interino do conselho, sr. dr. João Baptista Ortiz Monteiro. Diário Oficial da União, seção 1, p.5-7. 10 fev. 1918.

BRASIL.

Decreto n.11.530, de 18 de março de 1915 . Reorganiza o ensino secundário e superior da República. Disponível em: http://www2.camara. leg.br/legin/fed/decret/1910-1919/decreto-1153018-marco-1915-522019-republicacao-97760-pe. html. Acesso em: 1 abr. 2015. 18 mar. 1915.

\section{CERQUEIRA, Ede.}

A Sociedade Brasileira de Neurologia, Psiquiatria e Medicina Legal: debates sobre ciência e assistência psiquiátrica (1907-1933). Dissertação (Mestrado em História das Ciências e da Saúde) - Casa de Oswaldo Cruz/Fiocruz, Rio de Janeiro. 2014.

CURSO...

Curso de Medicina Pública. O Imparcial, p.1. 1 jun. 1917.
DOUTORES...

Doutores em saúde pública. A Rua, p.8. 20 dez. 1917.

GARZONI, Lerice de Castro.

Disputas políticas e disputas por leitores: a criação do Correio da Manhã (1898-1901). Topoi, v.12, n.22, p.158-177. jan.-jun. 2011.

\section{HEMEROTECA...}

Hemeroteca Digital Brasileira. A Noite. Rio de Janeiro: Fundação Biblioteca Nacional. Disponível em: http://hemerotecadigital.bn.br/ acervo-digital/noite/348970. Acesso em: 15 mar. 2014. s.d.

HÉRCULES, Hygino de Carvalho. Medicina legal. In: Gomes, Marleide da Mota; Vargas, Sylvia da Silveira Mello; Valladares, Almir Fraga (Ed.). A Faculdade de Medicina Primaz do Rio de Janeiro em dois dos cinco séculos de história do Brasil. São Paulo: Atheneu. 2001.

MAIO, Marcos Chor.

Afrânio Peixoto: notas sobre uma trajetória médica. Revista da SBPC, n.11, p.75-81. 1994. 
MAURY, Adriano (Ed.).

Anuário administrativo, agrícola, profissional, mercantil e industrial do Rio de Janeiro e indicador para 1908. Obra estatística e de consulta, fundada em 1844, por Eduardo von Laemmert com o título Almanak-Laemmert $65^{\circ}$ ano. Rio de Janeiro: Adriano Maury \& C. Disponível em: http://memoria.bn.br/DocReader/Hotpage/ HotpageBN.aspx?bib=313394\&pagfis=33527\&pes q=\&url\#. Acesso em: 31 mar. 2015. 1908.

NOTAS.

Notas. Arquivos Brasileiros de Psiquiatria, Neurologia e Ciências Afins, ano 3, n.4, p.435-436. out.-dez. 1907.

SAUER, Arthur (Org.).

Almanaque administrativo, mercantil e industrial do Rio de Janeiro e indicador para 1902. Obra estatística e de consulta, fundada em 1844, por Eduardo von Laemmert. Reformada e reorganizada por Arthur Sauer. $59^{\circ}$ ano. Rio de Janeiro: Companhia Tipográfica do Brasil. Disponível em: http:// memoria.bn.br/DocReader/docreader. aspx?bib=313394\&PagFis=21271. Acesso em: 31 mar. 2015. 1902.

SAUER, Arthur (Org.).

Almanaque administrativo, mercantil e industrial do Rio de Janeiro e indicador para 1895. Obra estatística e de consulta fundada em 1844 por Eduardo von Laemmert. Reformada e reorganizada por Arthur Sauer. Continuada e redigida pela Companhia Tipográfica do Brasil. $52^{\circ}$ ano. Rio de Janeiro: Companhia Tipográfica do Brasil. Disponível em: http://memoria.bn.br/ DocReader/DocReader.aspx?bib=313394\&PagFis= 9197\&Pesq=. Acesso em: 31 mar. 2015. 1895.

SBNPML.

Sociedade Brasileira de Neurologia, Psiquiatria e Medicina Legal. Boletim da SBNPML. Arquivos Brasileiros de Psiquiatria, Neurologia e Medicina Legal, ano 14, p.120-256. maio-set. 1918.

SERVIÇO...

Serviço Médico-Legal. Jornal do Brasil, p.7. 7 jan. 1916.

UM CURSO...

Um curso de medicina pública. Correio da Manhã, p.3. 18 maio 1918.

UM MONSTRUOSO...

Um monstruoso atentado à moral: o escandaloso caso do curso de medicina pública. A Noite, p.1. 25 maio 1918.

UM MONSTRUOSO...

Um monstruoso atentado. A Noite, p.1. 20 maio 1918.

VALVERDE, Belmiro.

Coisas médicas: o curso de medicina pública. Correio da Manhã, p.2. 24 maio 1917. 


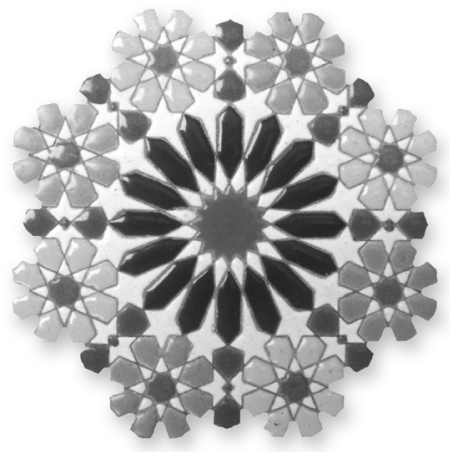




\section{ERRATA}

No texto "Variações sobre a 'cultura científica' em quatro autores brasileiros", de Marina Assis Fonseca e Bernardo Jefferson de Oliveira, publicado em História, Ciências, Saúde Manguinhos, v.22, n.2, jan.-abr. 2015:

- na página 447, quinto parágrafo, primeira linha, onde se lê "Miguel Ozorio de Almeida (1890-1953) era fisiologista e professor da Faculdade de Medicina", leia-se "Miguel Ozorio de Almeida (1890-1953), fisiologista, era professor da Escola Superior de Agricultura e Medicina Veterinária";

- na página 448, primeiro parágrafo, segunda linha, onde se lê "diretor do Instituto Oswaldo Cruz", leia-se "diretor da Seção de Fisiologia do Instituto Oswaldo Cruz".

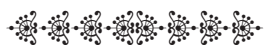

No texto da Nota de Pesquisa "A perícia médico-legal e o ensino: dissidências e discussões na Sociedade Brasileira de Neurologia, Psiquiatria e Medicina Legal”, de Ede Cerqueira, publicado em História, Ciências, Saúde - Manguinhos, v.22, n.2, jan.-abr. 2015:

- na página 642, terceiro parágrafo, última linha, onde se lê "SBNPML", leia-se "Serviço";

- na página 643, último parágrafo, segunda e terceira linhas, onde se lê "aulas teóricas. A cadeira prevaleceu", leia-se "aulas teóricas, prevalecendo";

- na página 644, segundo parágrafo, nona linha, onde se lê 'instituições se manifestaram contra a "implementação", leia-se 'instituições se manifestaram "no sentido de implementação"';

- na página 646, terceiro parágrafo, quarta e quinta linhas, onde se lê "e, possuindo caráter público", leia-se "e, já que esta possui caráter público".

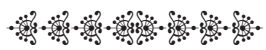

